\title{
La huelga del Colegio del Rosario y la Reforma Universitaria en Colombia (1930)*
}

\section{Resumen}

En este artículo se analiza la huelga de los estudiantes del Colegio Mayor de Nuestra Señora del Rosario, ocurrida en 1930. La importancia del conflicto radica en que propuso en el debate político la pertinencia de la reforma universitaria, una demanda impulsada infructuosamente por los estudiantes colombianos desde 1919. A partir de la reconstrucción de los planteamientos de los actores involucrados y la descripción de las tensiones políticas derivadas del conflicto, se resalta el valor simbólico que otorgaron los universitarios de Bogotá a la participación en la elección de las autoridades de las instituciones educativas, como ocurrió en el Colegio del Rosario en 1930. La interpretación de la huelga se realiza a partir de la lectura crítica de fuentes diversas: publicaciones periódicas y documentos oficiales de la época, y bibliografía secundaria sobre el Colegio del Rosario y la reforma universitaria en Colombia.

Palabras claves: Bogotá, Colegio del Rosario, huelga estudiantil, reforma universitaria.

Referencia para citar este artículo: DÍAZ JARAMILLO, José Abelardo (2017). "La huelga del Colegio del Rosario y la Reforma Universitaria en Colombia (1930)". En Anuario de Historia Regional y de las Fronteras. 22 (2). pp. 193-215.

Fecha de recepción: 01/08/2016

Fecha de aceptación: 03/03/2017

José Abelardo Díaz Jaramillo: Estudiante del Doctorado en Historia y magíster en Historia de la Universidad Nacional de Colombia, Colombia. Profesor de dedicación exclusiva de la Corporación Universitaria del Meta, Colombia, y está vinculado al Centro de Investigaciones Socio Jurídicas Jorge Eliecer Gaitán de la referida institución. Correo electrónico: jodiz16@yahoo.com. Código ORCID: 00000002-8457-3951.

\footnotetext{
* Artículo de investigación, producto de la tesis doctoral que realiza el autor sobre los estudiantes colombianos en la primera mitad del siglo XX.
} 


\title{
The Rosary School Strike and University Reform in Colombia (1930)
}

\begin{abstract}
Summary
In this article we analyze the students strike of the College of Our Lady of the Rosary, which took place in 1930. The importance of this conflict analysis is that brought to the political debate the relevance of the university reform, a claim driven unsuccessfully by Colombian students since 1919. From the reconstruction of the actors appeals and the description of the resulting political tensions of the conflict, the symbolic value of Bogotá's university students is emphasized through their participation in the officer's elections of the high educational institutions, as in the Rosary School in 1930. The interpretation of the strike is done from a critical reading of different sources: periodical publications and official documents of the time, and secondary literature of the Rosary School and university reform in Colombia.
\end{abstract}

Keywords: Bogotá, Colegio del Rosario, Student Strike, University Reform.

\section{Agreve do Rosário a Reforma Universitária na Colômbia (1930)}

\section{Resumo}

Neste artigo se analisa a greve dos estudantes do Colégio Maior de Nossa Senhora do Rosário, que ocorreu em 1930. A importância do conflito se radica na adição, no debate político, da pertinência da reforma universitária, uma demanda impulsionada em vão pelos estudantes colombianos desde 1919. A partir da reconstrução dos enfoques das partes interessadas e da descrição das tensões políticas resultantes do conflito, se ressalta o valor simbólico que outorgaram os universitários de Bogotá à participação na eleição das autoridades das instituições educativas, como ocorreu no Colégio do Rosário em 1930. A interpretação da greve é realizada a partir da leitura crítica de diferentes fontes: revistas e documentos oficiais da época, a literatura secundária no Colégio do Rosário e a reforma universidade na Colômbia.

Palavras-chave: Bogotá, Colegio del Rosario, greve estudantil, reforma universitária. 


\section{Introducción}

Los corredores penumbrosos del Colegio del Rosario, por donde cruzaron un día los graves varones de la emancipación, se llenan ahora con el grito de la muchachada rebelde. La huelga ha violentado las puertas y ventanas, y entra despertando todos los ecos revolucionarios que dormían en los rincones embrujados. [...] El conflicto se agudiza hasta la exasperación. Hay un sonoro desfile de muchachos entre

banderas entusiastas. El caserón se queda sólo y vacío. Sobre un portalón hidalgo un cartel flotante y desenfadado como una pirueta: "Se arrienda". Es la huelga que ha salido ahora a la calle entre un coro de estudiantes rebeldes. Y los graves señores, los profesores engomados, miran tras de las gafas pedagógicas, y no entienden lo que está pasando.

"La huelga en el Rosario", Mundo al Día, 16 de junio de 1930, p. 7.

El 18 de marzo de 1930 falleció en Bogotá Monseñor Rafael María Carrasquilla, quien oficiaba como rector del Colegio Mayor de Nuestra Señora del Rosario desde 1890. Según estaba contemplado en las Constituciones que regían el plantel desde los tiempos de la Colonia ${ }^{1}$, que al ocurrir la muerte del rector, el primer mandatario -primero el virrey y luego el presidente de la nación- debía escoger su reemplazo de una terna elegida por la Consiliatura del plantel. De modo que con la muerte del rector en ejercicio, las autoridades del Colegio se vieron abocadas a iniciar el proceso de elección para definir su reemplazo, un procedimiento interno que, como se verá, dio origen a la más resonada protesta estudiantil que se recuerde en la historia del Colegio Mayor de Nuestra Señora del Rosario².

Por cierto, la huelga del Rosario fue el más importante conflicto estudiantil registrado en 1930 en el pais ${ }^{3}$, justo en momentos en que expiraba la republica conservadora y el

\footnotetext{
${ }^{1}$ Fundado en 1653, el Colegio Mayor de Nuestra Señora del Rosario se regía por un conjunto de normas denominadas Constituciones, las cuales fueron aprobadas por la Corona en 1664 -y modificadas en distintos momentos-, reproduciendo el modelo del Colegio Mayor del Arzobispo de Salamanca. En las Constituciones quedó establecido que en las elecciones internas - durante los siglos XVII, XVIII y XIXdebían participar el rector y vicerrector, además de los 15 alumnos becados por la institución (aunque el número después varió), denominados colegiales formales y los becados por personas particulares denominados colegiales supernumerarios. El rector gobernaba conjuntamente con los consiliarios y, por encima de ellos, estaba el patrono o protector del Colegio, que durante el Virreinato de la Nueva Granada, era el virrey, y luego, durante el periodo de la República, el presidente. Guillen de Iriarte, María Clara. Rectores y rectorías del Colegio Mayor de Nuestra Señora del Rosario 1653-2003 (Bogotá: Academia Colombiana de Historia, 2003).

${ }^{2}$ Los conflictos estudiantiles no eran extraños en el Colegio del Rosario. Para el siglo XVIII, Diana Soto Arango ha estudiado un caso en "El movimiento de estudiantes y catedráticos en Santa Fe de Bogotá a fines del siglo XVIII", en Marsiske, Renate (coord.), Movimientos estudiantiles en la historia de América Latina, Tomo I (México D.F.: Universidad Autónoma de México, 1999). Para el siglo XIX se mencionan algunos conflictos estudiantiles en: Iriarte de Guillen, María Clara. Los estudiantes del Colegio Mayor de Nuestra Señora del Rosario 1826-1842 (Bogotá: Editorial Universidad del Rosario, 2008); y Mayorga García, Fernando. El Estado y el Colegio del Rosario en el siglo XIX: una historia de luces y sombras (Bogotá: Editorial Universidad del Rosario, 2010).

${ }^{3}$ La huelga de 1930 es mencionada por María Clara Guillen de Iriarte y Álvaro Pablo Ortiz (quien se apoya en las descripciones de Guillen de Iriarte) en investigaciones que reconstruyen la historia del plantel educativo, aunque sin efectuar una interpretación del conflicto que vaya más allá del asunto normativo del Colegio, y lo relacione, por ejemplo, con factores ligados a las demandas estudiantiles por
} 
liberalismo se aprestaba a asumir el control del Estado. Varias razones permiten resaltar la importancia del conflicto: su origen estuvo ligado al interés de los estudiantes por participar en la elección de las autoridades internas del plantel, una demanda que se conectaba con los reclamos que venían desde los tiempos de la Reforma de Córdoba (1918); además, el conflicto mostró el protagonismo político del gremio estudiantil en la capital, que se expresó a través de la acción coordinada y la solidaridad; por último, la huelga obligó al Estado a intervenir, pese a las características administrativas del plantel, lo cual abrió de nuevo el debate sobre la pertinencia de una reforma universitaria en el país, con un papel protagónico del Estado en su orientación.

Por estas razones, en las líneas siguientes se analizará la huelga del Colegio del Rosario a partir de la identificación de las causas inmediatas que motivaron la reacción de los estudiantes del plantel, y el curso que tomaron los hechos; asimismo, la exposición del papel de la agremiación estudiantil bogotana en la huelga, para lo cual se sostendrá que éste estuvo determinado por el interés de reivindicar la pertinencia de la reforma universitaria en Colombia; de igual modo, la explicación de las tensiones surgidas al interior del gobierno conservador, derivadas del rumbo que tomó el conflicto estudiantil. Al final se establecerán, a modo de conclusiones, algunas líneas de interpretación del acontecimiento estudiado.

\section{Elección del rector}

Según disponían las Constituciones del Colegio del Rosario, la elección del rector debía realizarse a través de un proceso que comenzaba con la apertura formal por parte del Presidente de la Republica, Patrono del Colegio, continuaba con la elección de una terna de tres candidatos y finalizaba con la escogencia del rector de la lista de los ternados por el primer mandatario de la nación. El sistema de elección de la terna, que podía durar varios días, tenía un carácter restrictivo: únicamente podían participar los diez colegiales ${ }^{4}$, el rector encargado, el secretario y los tres miembros de la Consiliatura. De tal modo que para la elección de 1930 solo tomaría parte el rector encargado Jenaro Jiménez, el secretario Pedro Ramírez Toro, los consiliarios José Antonio Montalvo, Emilio Ferrero y Francisco María Rengifo y diez alumnos especiales, de una población conformada por cerca de doscientos cincuenta estudiantes ${ }^{5}$.

la democratización de los planteles educativos del país. Guillen de Iriarte, María Clara. Op Cit., y Ortiz Rodríguez, Álvaro Pablo. Historia de la Facultad de Filosofía y Letras del Colegio Mayor de Nuestra Señora del Rosario 1930-1999 (Bogotá: Editorial Universidad del Rosario, 2006).

${ }^{4}$ En el Colegio del Rosario existían cuatro categorías de alumnos: los colegiales, que gozaban de prerrogativas que no tenían los demás, como ser electores de las autoridades del plantel y gozar de una beca gratuita; los convictores, que pagaban su pensión alimenticia; los oficiales, que tenían beca gratuita, a cambio de prestar algunos servicios en el colegio; por último, los externos, que asistían a las clases y presentaba exámenes a fin de año. Revista del Colegio Mayor de Nuestra Señora del Rosario, Bogotá, pp. 319 y 320; Guillen de Iriarte, María Clara, Op Cit., pp. 66 ss.

${ }^{5}$ Los siguientes datos permiten apreciar, cuantitativamente, el número de estudiantes matriculados en el colegio y la diferencia entre los alumnos internos y los externos: en diciembre de 1929, seis meses antes de la huelga, habían terminado el año escolar 234 alumnos (154 internos y 80 externos); en 1931 concluyeron el año escolar 180 alumnos (100 internos y 80 externos); y en 1932 se matricularon 297 estudiantes (190 
El proceso para elegir al rector tuvo un carácter controversial desde el principio. La mayoría de los estudiantes internos, sin derecho a participar directamente en la elección, decidieron impulsar, junto a algunos colegiales, la candidatura del sacerdote y secretario del arzobispado José Alejandro Bermúdez, a quien consideraban como un abanderado de la reforma universitaria y de la modernización de las "añejas tradiciones rosaristas" rectoría de monseñor Carrasquilla. Para impulsar el nombre de Bermúdez, los estudiantes conformaron un comité integrado por representantes de todos cursos del colegio, el cual realizó una activa campaña que le dio al proceso de elección de rector un aire diferente entre la comunidad estudiantil.

Figura 1. José Alejandro Bermúdez dibujado por Rendón.

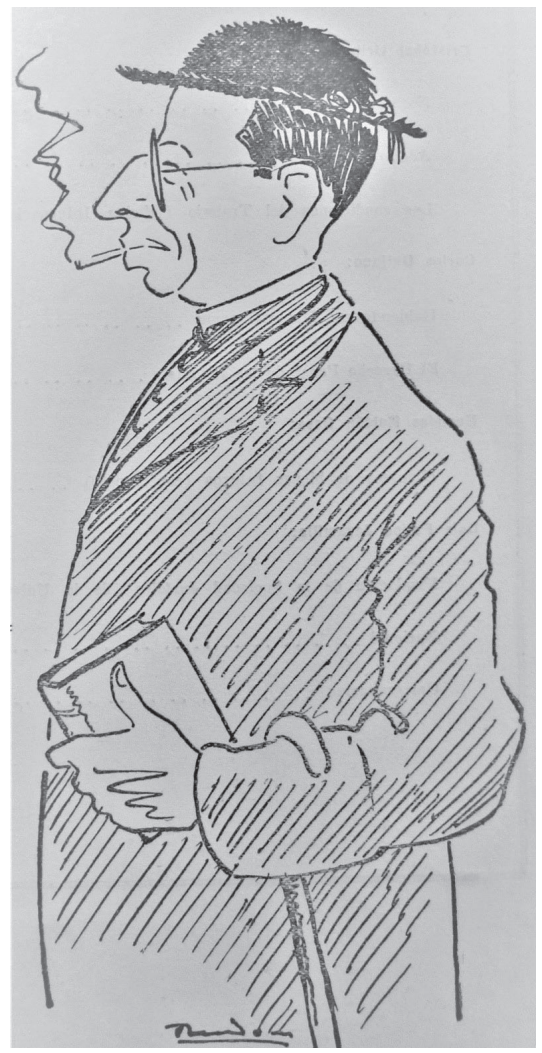

Fuente: Revista Jurídica, Bogotá, 1927.

internos y 107 externos). Revista del Colegio Mayor de Nuestra Señora del Rosario, Bogotá, p. 319, 320; Memoria del Ministro de Educación al Congreso (Bogotá: s.e., 1932), pp. 77, 79 y 80. Si bien no se cuenta con datos de 1930, se puede establecer, observando los datos de 1929 y 1931, que era mayor el número de estudiantes internos.

6 "Los estudiantes del Rosario proyectan hacer la huelga", El Diario Nacional, Bogotá, 14 de junio de 1930, p. 1. ss; mientras que los otro cuatro colegiales de número eran partidarios de la candidatura de Bermúdez. "Hoy se elige nuevo rector del Rosario", El Tiempo, Bogotá, junio 14 de 1930, p. 1. 
Durante los días 11, 12 y 13 de junio de 1930 los miembros del cuerpo elector se reunieron para realizar las tres consultas previas para escoger la terna para rector. De acuerdo a las actas de las sesiones electivas, el candidato José Vicente Castro Silva tenía el favoritismo desde la primera consulta, al obtener 14 votos; mientras que José Alejandro Bermúdez ocupó el segundo lugar, con 9 votos; seguido de José María González Valencia, con 5 votos $^{7}$. En la tercera consulta los votos siguieron favoreciendo al candidato José Vicente Castro, mientras que Bermúdez cayó al quinto lugar, sumando apenas seis votos ${ }^{8}$.

La elección definitiva se realizó el 14 de junio en el Aula Máxima del Colegio. Antes de abrir la votación y después de haber rezado el Ave María, el rector interino hizo lectura de algunos capítulos del estatuto orgánico del colegio que se referían al acto que iba a celebrarse. Intervino enseguida el consiliario Emilio Ferrero, quien pidió a los estudiantes aceptar el fallo, aun si este no era del agrado de todos. En un ambiente ya tenso, las declaraciones de Ferrero causaron un profundo malestar, que vino a agudizarse cuando se dio a conocer el resultado final de la votación: José Vicente Castro Silva obtenía 14 votos; Antonio Gómez Restrepo, 11 votos; José María González, 9 votos; José Alejandro Bermúdez, 4 votos; Alberto Goenaga, 3 votos y Jenaro Jiménez, 3 votos. Así las cosas, la terna oficial quedó conformada por José Vicente Castro Silva, Antonio Gómez Restrepo y José María González Valencia, mientras que el candidato que era apoyado por la mayoría de los estudiantes quedó excluido?.

Una vez se conoció el resultado, una protesta generalizada se apoderó del claustro. Los estudiantes, molestos, consideraron que la no inclusión de José Alejandro Bermúdez en la terna escogida, iba en contra del "deseo de la mayoría"10, y cuestionaron el sistema consignado en los cánones orgánicos del colegio, que les prohibía tomar parte efectiva en la elección del rector de la institución. Enseguida, desde el segundo piso del plantel, el profesor Carlos Lozano y Lozano pronunció unas palabras pidiendo cordura a los estudiantes, pero también censurando la actitud de la Consiliatura por los resultados de la elección. Cuando concluía su intervención, el rector Jiménez, en un acto inaudito, se abalanzó sobre los estudiantes para arrebatarles la bandera del plantel que minutos antes estos habían sustraído de la sacristía de la capilla, lo que dio origen a una trifulca. En cuestión de segundos, el rector logró hacerse a la bandera y huir por los corredores del claustro, seguido por algunos colegiales y consiliarios. Con enfado, los estudiantes salieron a la calle, acompañados por colegas de otras facultades que habían sido convocados en actitud de apoyo. Desde los balcones del Café Riviera, con encendidos discursos, algunos estudiantes atacaron a José Antonio Montalvo,

\footnotetext{
${ }^{7}$ Ibid.

${ }^{8}$ Ibid.

${ }^{9}$ Las actas de las elecciones fueron publicadas en la Revista del Colegio Mayor de Nuestra Señora del Rosario, Bogotá, agosto de 1930.

${ }^{10}$ Finalmente, fue escogido por el presidente Abadía Méndez, a través del decreto 987 del 21 de junio de 1930, el nombre de José Vicente Castro Silva, como rector del Colegio del Rosario. Guillen de Iriarte, María Clara, Op Cit.; p. 552.
} 
consiliario a quien responsabilizaron de lo ocurrido. Posteriormente, se dirigieron por la carrera séptima hacia la calle 11, a la casa de José Alejandro Bermúdez, ausente en ese momento, circunstancia que los motivó a dirigirse a las facultades ubicadas en el centro de la ciudad.

Frente a la Facultad de Ingeniería, el estudiante Juan B. Barrios invitó a los manifestantes a no ceder en la campaña por la "reforma de la constitución rosarista"11. Luego, se movilizaron hacia la Casa del Estudiante, en donde los rosaristas Héctor Martínez Guerra y Alejandro Venegas, en discursos emotivos, pidieron a las directivas de la Federación Nacional de Estudiantes (FEN) el apoyo "para llevar la reforma universitaria a todas sus consecuencias y a todos los rincones"12. El presidente de la FEN, Diego Luis Córdoba, quien expresó la solidaridad absoluta de la agremiación, indicó que con la actitud asumida por los alumnos rosaristas se declaraba oficialmente la huelga estudiantil, la cual debía empezar de manera simultánea en todos los planteles del país, y no cesaría hasta tanto no se consiguiera la reforma en el Colegio del Rosario ${ }^{13}$.

La inédita situación motivó a un grupo de profesores del plantel -comisionados por los estudiantes- $-^{14}$, entre quienes sobresalía Carlos Lozano y Lozano y Eduardo Zuleta, a buscar una entrevista con el Ministro de Educación, Eliseo Arango, para motivar su intervención en el conflicto. Tal interés estaba orientado por una lectura acertada que hacían los estudiantes y profesores del joven ministro, a quien veían como un partidario de la reforma educativa en el país ${ }^{15}$. En efecto, el ministro Arango reconoció que si bien el Colegio del Rosario se regía de forma independiente, no podía ver con indiferencia lo que allí estaba sucediendo, por lo que anunció que intervendría para encontrar una solución pronta que beneficiara a las dos partes. Si bien los profesores y el propio ministro eran partidarios de la reforma en el Rosario, contemplaron como salida a la crisis el cambio de la terna escogida, para poder incluir el candidato de los estudiantes. Sin embargo, reconocieron que esa salida obligaba a cambiar la normatividad del colegio, algo que no podría hacerse pronto.

Surgió entonces otra salida: como ni José Castro Silva ni Antonio Gómez Restrepo, primero y segundo en la terna elegida, se encontraban en el país, se pediría al Presidente Miguel Abadía Méndez, Patrono del Colegio, que eligiera a José María González

\footnotetext{
${ }^{11}$ Guillen de Iriarte, María Clara. Op Cit., p. 551.

12 “Los rosaristas quieren que se elija una nueva terna para rector", El Tiempo, Bogotá, 15 de junio de 1930, p. 1. ${ }^{13}$ Ibid.

${ }^{14}$ Entre las decisiones adoptadas por los estudiantes del Rosario, se registra la realización de una junta general de donde debía salir una comisión para dirigir el movimiento, integrada por Juan B. Barrios, Jesús Estrada Monsalve, Héctor Martínez, Alejandro Vanegas y Julio Ortiz Márquez. "Los rosaristas quieren que se elija una nueva terna para rector", El Tiempo, Bogotá, 15 de junio de 1930, pp. 1 y 13; "La huelga en el Colegio del Rosario", Mundo al Día, Bogotá, 16 de junio de 1930, p. 13.

${ }^{15}$ Desde un comienzo los profesores jóvenes del colegio se solidarizaron con los estudiantes, manifestando la disposición de acompañarlos en el movimiento de protesta. Tal postura deja entrever posibles tensiones al interior del cuerpo de profesores de la institución, por criterios en torno al discurso modernizador de la educación que estaba presente en el país desde hacía algún tiempo.
} 
Valencia, el tercero de la terna, quien enseguida presentaría la renuncia para que el Presidente Abadía Méndez pudiese nombrar un rector interino, con prescindencia de la Consiliatura, para cuyo cargo los estudiantes tenían como candidato al profesor Esteban Jaramillo. Como rector interino, Jaramillo quedaría con la facultad de nombrar los consiliarios, uno de los propósitos que buscaban los estudiantes. En este momento, se supondría, renunciaría Jenaro Jiménez y, con el nuevo estado de cosas creado, y admitiendo la rectoría efectiva del primero de los candidatos que figuraba en la terna, sería posible promover la reforma integral en los estatutos constitucionales y en los reglamentos.

La farragosa formula fue presentada por una comisión de profesores al Presidente Miguel Abadía Méndez, quien la rechazó sin vacilación, aduciendo "[...] que no podía intervenir por las mismas razones de la independencia con que se regían los asuntos del Rosario"16. Los profesores rápidamente intentaron persuadir al mandatario, reconociendo como justas las demandas de los estudiantes y manifestando el temor de que la crisis adquiriera mayor dimensión, y condujera al cierre del establecimiento. No obstante, el primer mandatario insistió en que esa era su posición.

¿Cómo entender el comportamiento del primer mandatario ante la crisis que se abría paso en la capital del país? Al respecto, es evidente que en el Presidente Abadía Méndez pesaban hechos que es necesario advertir. Por ejemplo, que algunos de los implicados en el conflicto (por ejemplo, los consiliarios), habían sido ministros en gobiernos conservadores anteriores e incluso del suyo ${ }^{17}$. Otro hecho importante es que el Presidente Abadía Méndez tenía presente en la memoria los hechos de junio de 1929 en Bogotá, cuando un movimiento ciudadano provocó una aguda crisis que afectó su gobierno, y que tuvo consecuencias decisivas para el Partido Conservador. Varios de los protagonistas del conflicto estudiantil de 1930, habían tomado parte en las protestas de 1929, entre ellos, las agremiaciones estudiantiles de la capital ${ }^{18}$. De modo que, el Presidente Abadía Méndez, pronto a entregar el poder al liberal Enrique Olaya Herrera, poco interés tenía en satisfacer los deseos de sectores que meses atrás habían desatado una movilización en la capital para denunciar a su gobierno.

\section{Se declara la huelga estudiantil}

Una vez se conoció la postura del Presidente Abadía y la decisión de la Consiliatura de negarse a dialogar ${ }^{18}$, la agitación se apoderó de la Casa del Estudiante. El estudiante Héctor Martínez Guerra exhortó a sus compañeros a decretar la huelga y a acudir al plantel para sacar de los dormitorios los colchones y, con ellos a cuesta por las calles,

\footnotetext{
${ }^{16}$ A Eliseo Arango se le recuerda por su vinculación al grupo de jóvenes conservadores conocido como Los Leopardos, aunque es poco lo que se conoce de su trayectoria política más allá de los años veinte. Sobre Eliseo Arango y Los Leopardos: Arias, Ricardo. Los Leopardos. Una historia intelectual de los años 1920 (Bogotá: Uniandes-Ceso, 2007).

17 "La huelga en el Colegio del Rosario", Mundo al Día, Bogotá, 16 de junio de 1930, p. 13; "Los rosaristas quieren que se elija una nueva terna para rector", El Tiempo, Bogotá, 15 de junio de 1930, pp. 1 y 13.

${ }^{18}$ Por ejemplo: José Antonio Montalvo, egresado del Colegio del Rosario, fue Ministro de Industrias (19271929) en el gobierno de Miguel Abadía Méndez; y Emilio Ferrero fue Ministro de Instrucción Pública entre 1914 y 1918, durante el gobierno del presidente José Vicente Concha.
} 
demostrar "[...] que [...] no estaban en disposición de someterse incondicionalmente $\mathrm{y}$ a que se les siguiera tratando en esa forma despectiva y humillante"19. La propuesta fue acogida de inmediato por todos los estudiantes, quienes, lanzando ¡vivas! al cuerpo de profesores y ¡abajos! a personajes de la política y del gobierno, acudieron a los dormitorios del Colegio del Rosario, dejándolos vacíos en cuestión de minutos. Luego, cuando ya ocupaban la calle, uno de ellos, Juan de Dios Jaramillo, se subió a una pirámide formada por colchones, y pronunció un encendido discurso en donde invocó firmeza para conseguir la reforma de las "[...] arcaicas disposiciones del Colegio y a no dejarse vencer por el capricho de los señores que integran la Junta de Consiliatura, y que son los que han originado el conflicto" ${ }^{20}$. De paso, elogió el orador la solidaridad de los compañeros de otros establecimientos, e invitó a los rosaristas a “[...] acogerse al alero protector y amplio de la casa del estudiante (sic), donde no se les negaría el albergue y en donde sus ideas renovadoras encontrarían firme apoyo"21.

En efecto, los rosaristas se dirigieron de nuevo a la Casa del Estudiante, donde fueron recibidos con algarabía por los estudiantes federados, quienes pusieron a su disposición todos los servicios que allí se ofrecían. En el patio principal de la edificación, los rosaristas formaron una vez más una pirámide de colchones que sirvió de tribuna a un alumno de Medicina, quien, en emotivas frases, pidió "[...] a todos los estudiantes de Bogotá a mirar como propia la causa de los rosaristas y a prestar cada cual su contingente en la medida de sus fuerzas para dar albergue íntegramente a todos"22. Sucedió enseguida un hecho de un notable efecto simbólico: jóvenes de otros establecimientos educativos invitaron a dos, tres y hasta cuatro rosaristas, a hospedarse en sus apartamentos y pensiones, mientras que la Universidad Libre ofreció un salón para alojar a 30 o 40 rosaristas. A su vez, un directivo del Centro Departamental de Estudiantes anunció que la Casa del Estudiante ofrecería alimentación gratuita a todos los huelguistas. Como se puede ver, un espontáneo espíritu de compañerismo y solidaridad germinó en los albores de la protesta estudiantil, expresión que fue respondida con aplausos por los rosaristas, quienes "así comprobaron como todo el gremio está con ellos en su generosa campaña renovadora" ${ }^{23}$.

\footnotetext{
${ }^{19}$ La prensa liberal difundió la versión que en la reunión en Palacio, el presidente Abadía se había mostrado disgustado con la presencia de Carlos Lozano y Lozano, uno de los miembros de la comisión que visitó al mandatario, a quien le manifestó su extrañeza de verlo, sabiendo el presidente Abadía que, en las jornadas del 8 de junio de 1929, aquel había pedido su cabeza. Esta versión, sin embargo, fue desmentida por el propio Abadía a través de la misma prensa. "El Dr. Abadía y su intervención en el conflicto del Rosario", Mundo al Día, Bogotá, 17 de junio de 1930, p. 3.

20 "Hoy se elige nuevo rector del Rosario", El Tiempo, Bogotá, 14 de junio de 1930, p. 1.

21 "El gobierno abrió las matriculas para los rosaristas", El Tiempo, Bogotá, 31 de julio de 1930, p. 5.

22 "Los rosaristas quieren que se elija una nueva terna para rector", El Tiempo, Bogotá, 15 de junio de 1930, p. 1, 13 y última. Como se indicó anteriormente, la mayoría de estudiantes del Colegio del Rosario era internos, es decir, dormían en el plantel, al carecer de recursos económicos suficientes para poder sostenerse fuera de sus instalaciones.

23 "El gobierno abrió las matriculas para los rosaristas", El Tiempo, Bogotá, 31 de julio de 1930, p. 5.
} 
La decisión de abandonar las instalaciones del Colegio vino acompañada de la conformación de una guardia estudiantil que tenía la misión de vigilar las puertas del colegio y evitar el ingreso de estudiantes, con lo cual se pondría en riesgo la efectividad de la huelga ${ }^{24}$. Para reforzar el mensaje que pretendían enviar a las autoridades del plantel, ubicaron a la entrada principal un gran letrero que decía "Se arrienda"

Imagen 1. Los rosaristas abandonan el colegio con los colchones a las espaldas.

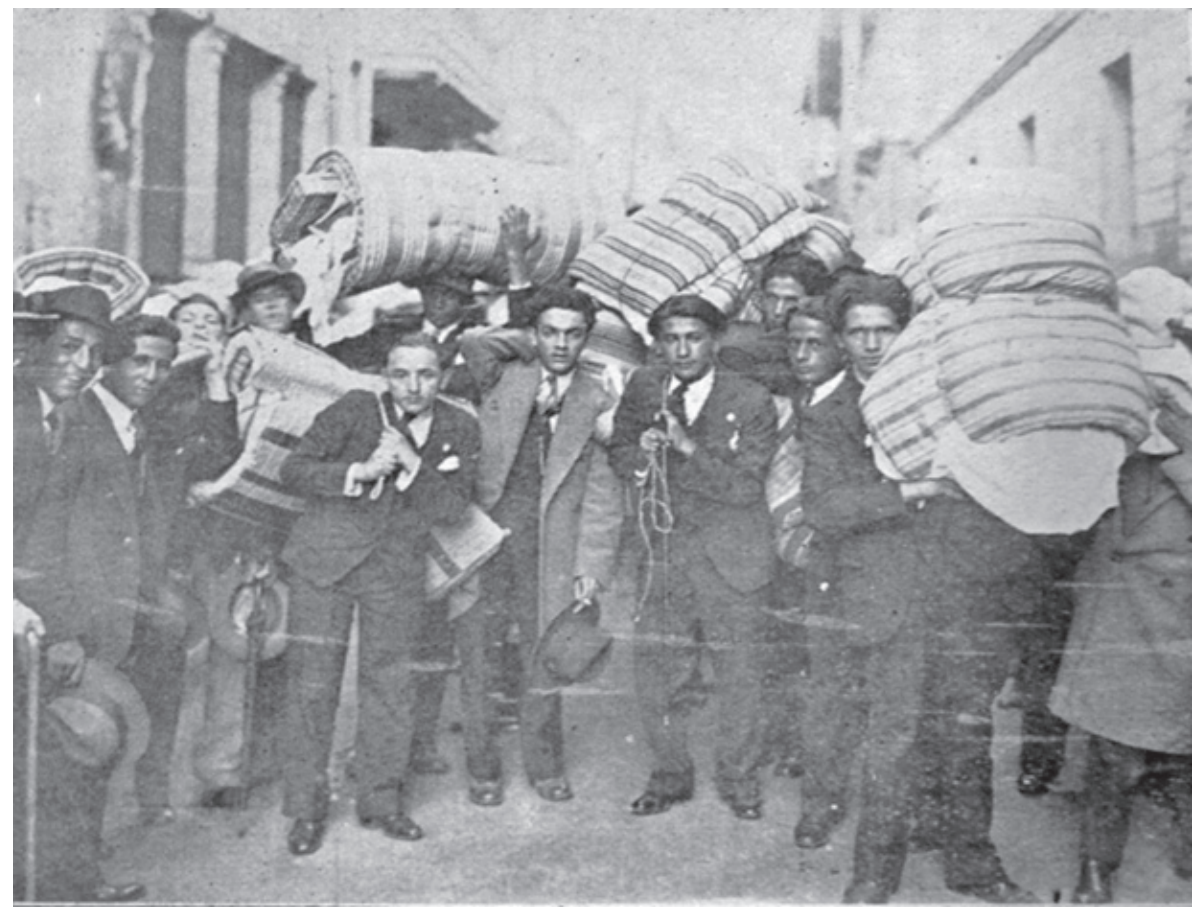

Fuente: Cromos, Bogotá, junio 21 de 1930, p. 19.

Sin duda, las decisiones adoptadas por los estudiantes afectaron la legitimidad de la Consiliatura y del rector interino. A los ojos del público, tanto los consiliarios como el rector Jiménez representaban la autoridad de una institución educativa que carecía de estudiantes. Ante esos hechos, uno de los consiliarios, Emilio Ferrero, afirmó que “[...] los estudiantes descontentos, que [...] quisieran abandonar el establecimiento, naturalmente tenían toda la libertad para hacerlo, aun cuando tal determinación sería muy sensible para la Consiliatura"26. En un tono diferente, el rector Jenaro Jiménez declaró: "[...] quienes no quieran volver, que no vuelvan. Estoy seguro de que cuarenta estudiantes no se retirarán un solo día del claustro". La declaración no fue,

\footnotetext{
${ }^{24} \mathrm{La}$ actuación de la guardia estudiantil originó algunos inconvenientes. Por ejemplo, en una ocasión un alumno de literatura y oficial becado del colegio, amenazó revolver en mano a los universitarios que montaban guardia, los cuales lo desarmaron y lo entregaron a la policía.

25 "La huelga en el Rosario", Mundo al Día, Bogotá, 16 de junio de 1930, p. 7.

26 "Los rosaristas quieren que se elija una nueva terna para rector", El Tiempo, Bogotá, 15 de junio de 1930, pp. 13 y última.
} 
por supuesto, la más indicada en un momento crítico como el que se registraba en el Colegio del Rosario. Enseguida, los estudiantes le respondieron con contundencia: "Ninguno de nosotros volverá a pisar el plantel mientras no se haya solucionado el conflicto de manera favorable a nuestros anhelos"27.

Los cuestionamientos de los estudiantes se extendieron a algunos directivos del Colegio. Por ejemplo, acusaron al consiliario José Antonio Montalvo por "burlar la opinión de los rosaristas" 28 , y le pidieron la renuncia inmediata de los cargos de consiliario y profesor. Los estudiantes en carta dirigida a Montalvo afirmaron:

Desde hace varios meses sus alumnos de Derecho Penal estamos deseosísimos de obtener su renuncia de dicha cátedra. No es esta una resolución tomada en tiempos de acaloramiento; para probar a usted esto, estamos dispuestos a someter las conferencias que usted ha venido dictando, a un tribunal de arbitramento, integrado por personas escogidas por usted mismo entre las mejores capacidades en la materia. Es esta la manera como quiere obrar una juventud noble y generosa, aun para con quienes, quizá debido a su temperamento, han querido traicionarla ${ }^{29}$.

En las posturas de los rosaristas era evidente una seguridad en sus convicciones, lo que se explica, en parte, por el apoyo amplio que recibieron de sectores políticos y académicos de la sociedad. Por ejemplo, el rector de la Universidad Libre, Jorge Soto del Corral, en una nota dirigida al comité de huelga rosarista, lamentó que la Consiliatura del Colegio hubiera roto "[...] la armonía indispensable entre profesores y estudiantes, que no son elementos divergentes sino partes componentes de un solo organismo que no deben tener otra norma que la cooperación" ${ }^{30}$. Además, en un acto provocador, invitó a los miembros del comité de huelga a visitar la Universidad Libre, donde serían "recibidos con la mayor amistad en todo momento en que lo crean conveniente"31. En la misma dirección, el consejo estudiantil de la Facultad de

27 "Los rosaristas quieren que se elija una nueva terna para rector", El Tiempo, Bogotá, 15 de junio de 1930, pp. 1, 13 y última.

${ }^{28}$ En declaraciones a la prensa, Montalvo indicó que la decisión de no incluir el nombre de José Alejandro Bermúdez en la terna se debió a “[...] la imposibilidad moral en que estaba el cuerpo de electores de permitir que sobre su conciencia se hiciera una imposición extraña, por bueno e ilustre que fuera el candidato que se quisiera imponer". Y agregó: “Todos sus miembros juraron proceder rectamente y elegir según Dios y su conciencia, sin admitir imposiciones ni siquiera influencias extrañas, cosa que deben jurar como en efecto juraron, los electores sobre los santos Evangelios, antes de proceder a la elección". "Los rosaristas quieren que se elija una nueva terna para rector", El Tiempo, Bogotá, 15 de junio de 1930, pp. 1 y 13. Si bien Montalvo presentó su renuncia a la cátedra en el Colegio, no lo hizo de la Consiliatura, porque "en él represento a la autoridad", y no lo haría "mientras no se haga la elección de los consiliarios como mandan nuestras constituciones". "Renuncia de un profesor", en Revista del Colegio Mayor de Nuestra Señora del Rosario, Bogotá, agosto de 1930, p. 509.

29 "Los rosaristas quieren que se elija una nueva terna para rector", El Tiempo, Bogotá, 15 de junio de 1930, pp. 1, 13 y última.

30 "Los rosaristas quieren que se elija una nueva terna para rector", El Tiempo, Bogotá, 15 de junio de 1930, pp. 1, 13 y última.

${ }^{31}$ Ibid. Habían otras demandas de los rosaristas: la revisión del pensum de la Facultad de Derecho y de Literatura, la elección de rector por los alumnos de la Facultad y por representantes de los alumnos de bachillerato, la creación de la figura del profesor agregado y la creación de seminarios. La resolución Elvira 
Derecho de la Universidad Libre respaldó a los rosaristas, a quienes se había tratado, según señalaba, como "[...] un accidente dentro del claustro y no como una fuerza integrante de las disciplinas docentes"32. Por ese motivo, expresó su apoyo “[...] en la consecución de los fines que se proponen alcanzar para que sus deseos no sean burlados y supeditados por el antiquísimo principio de autoridad, que debe despojarse totalmente de los centros educacionistas" ${ }^{\prime 3}$.

El Centro Departamental de Estudiantes a su vez, emitió una resolución en donde cuestionó el desconocimiento de los derechos de los estudiantes hecha por la Consiliatura y la mayoría de los colegiales, a quienes señaló de haber traicionado "la voluntad manifiesta de sus compañeros de aulas" ${ }^{34}$. Destacaba el gremio departamental que la exclusión del candidato José Alejandro Bermúdez en la formación de la terna era "apenas un incidente" 35 , ya que lo realmente importante que buscaban los estudiantes era la reforma de las "constituciones oligárquicas" 36 que regían el Colegio del Rosario, plantel al que veían como un "herrete medieval"37.

La prensa liberal de la capital también salió en defensa de los rosaristas. El Tiempo afirmó que la inconformidad estudiantil no era producto de la terna, compuesta de "hombres respetables, probos y capaces" 38 , sino de la forma como se había conformado, con el propósito de detener los anhelos estudiantiles. El diario se preguntaba:

¿Por qué esa resistencia sistemática a los deseos de los estudiantes? ¿Por qué no reconocerles la razón, cuando la tienen, y no admitir hechos como el de la popularidad de un candidato, cuando ese candidato es plenamente digno del honor que se le quiere otorgar? La teoría de que no se puede ceder a la presión, es una teoría que debe tener sus límites y que como única norma de acción no se justifica máxime cuando esa presión no tenía caracteres reprobables ningunos, y era solo una manifestación de merecida simpatía ${ }^{39}$.

Campuzano Racines, Guillermo Sarmiento González, Enrique López de la Pava, José Joaquín Rodríguez, Luis García, Mauricio Guerra.

32 "El conflicto del Rosario", El Tiempo, Bogotá, 15 de junio de 1930, p. 5.

33 "La Huelga", Mundo al Día, Bogotá, 20 de junio de 1930, p. 7.

34 “El Dr. Abadía y su intervención en el conflicto del Rosario", Mundo al Día, Bogotá, 17 de junio de 1930, p. 3.

35 "Los consiliarios del Rosario no aceptan el decreto del doctor Abadía Méndez", El Tiempo, Bogotá, 24 de junio de 1930, pp. 1 y última.

36 "Hay que salvar el Colegio del Rosario", El Tiempo, Bogotá, junio 25 de 1930, p. 5.

37 "No puede condenarse a la holganza a una multitud de muchachos", Mundo al Día, Bogotá, 25 de junio de 1930, p. 4.

38 "Se agrava nuevamente el conflicto en el Rosario", El Tiempo, Bogotá, junio 29 de 1930, pp. 1 y 3.

${ }^{39} \mathrm{La}$ reacción de los estudiantes se alimentó, en parte, de lo informado por los diarios liberales. Por ejemplo, El Nuevo Tiempo señaló que los consiliarios habían puesto como condición para solucionar el conflicto, la entrega de los nombres de los líderes de la protesta estudiantil, hecho que fue negado por el consiliario Emilio Herrera en una comunicación dirigida al director del periódico, en donde indicó lo siguiente: "Aun cuando es notorio que las autoridades y reglamentos del colegio han sido objeto de un grave desacato por parte de los alumnos que de su propia voluntad han abandonado el plantel, ninguna exigencia de desagravio ha hecho sin embargo la Consiliatura, ni yo hablé palabra en tal sentido al señor doctor Arango. Muchísimo menos le ha ocurrido ni podrá ocurrirle a ese cuerpo directivo, formado como esta de caballeros, pensar siquiera en el ruin expediente de la delación. Ha querido la Consiliatura (sic), eso 
En la misma dirección, Mundo al Día resaltó que la actitud de los estudiantes rosaristas era "ampliamente razonable" ${ }^{40}$, más allá de que no se hubiera incluido el nombre del presbítero Bermúdez en la terna, por los anhelos estudiantiles "por la reforma integral en la organización del Colegio del Rosario"41.

Estas expresiones de apoyo de la prensa ponen de presente que los rosaristas gozaban de un evidente respaldo externo, pero también demuestran el interés de sectores políticos, particularmente ligados al liberalismo, por intervenir en el conflicto, motivados por la concepción de que allí se libraba una batalla contra un modelo de educación tradicional que impedía la modernización del país.

\section{El gobierno interviene}

El curso que tomaron los hechos obligó al gobierno a modificar la postura que adoptó al comienzo, probablemente para demostrar que la hostilidad hacia los estudiantes en huelga no era cierta, como aseveraban algunos periódicos. Es en esos términos que se comprende que el presidente Abadía dio una mayor libertad al ministro Eliseo Arango, para encontrar una solución a la crisis, e incluso, que lo hubiese autorizado para actuar con firmeza ante las autoridades del Colegio del Rosario, dispuestas, como se mostró, a no ceder ante los reclamos de los estudiantes.

En una reunión convocada por el ministro Arango con los consiliarios y profesores, a la cual también asistieron representantes de los estudiantes ${ }^{42}$, se divisaron dos posibles salidas por parte de los profesores y estudiantes: que los consiliarios reconsideraran la elección de la terna, para incluir el nombre de José Alejandro Bermúdez, o que renunciaran, para no complicar más situación. Las dos posibilidades, como se deduce, pusieron en manos de los consiliarios la solución a la crisis; sin embargo, en forma categórica, éstos expresaron que de ningún modo contemplarían cualquiera de las dos salidas, y reiteraron la decisión de esperar la llegada al país del nuevo rector.

sí, y su derecho para exigirlo es innegable, que los alumnos dispuestos a retornar al claustro lo manifiesten así al rector, comprometiéndose a acatar debidamente las autoridades y reglamentos del instituto. Menos no se puede pedir, y eso poco que se pide es algo que ningún alumno podría razonablemente excusar, si es que de veras se busca el ordenado y buen funcionamiento del colegio". "La Consiliatura del Rosario no ha hecho exigencias de desagravio", El Tiempo, Bogotá, julio 1 de 1930, p. 4.

40 "Se hacen esfuerzos para dar solución a la huelga del Rosario", El Tiempo, Bogotá, 30 de junio de 1930, pp. 1 y 12.

${ }^{41}$ Ibid.

${ }^{42}$ Las relaciones entre el Colegio del Rosario y el Estado, particularmente en el siglo XIX, fueron conflictivas. Luego de la independencia de España, el Patronato del colegio fue asumido por el Jefe de Estado, que lo utilizó en varias ocasiones para centralizar su autoridad sobre el plantel. Esto fue evidente en 1826, cuando Francisco de Paula Santander promovió la Universidad Central en Bogotá. En 1860, el Intendente del Distrito Nacional de Cundinamarca decretó la expropiación del Colegio y lo convirtió en cárcel; al año siguiente, con la ley de desamortización de bienes de manos muertas, el Colegio se vio afectado. Sin embargo, en 1892, en tiempos de la Regeneración, el Estado le concedió una amplia autonomía al Colegio. Sobre este tema se puede consultar a Gaitán Bohórquez, Julio. El Colegio del Rosario y el proyecto decimonónico de universidad en Colombia: un intento de reconstrucción desde la normatividad (Bogotá: Centro Editorial Rosarista, 2002); y a Mayorga García, Fernando, Op Cit. 
En vista de que esa postura complicaba las cosas, al gobierno pareció no quedarle otra salida que ordenar, por decreto, la conformación de una nueva Consiliatura. La medida, por supuesto, fue rechazada por los consiliarios y por el rector provisional, que en un gesto de solidaridad con aquellos, procedió a cerrar el colegio hasta el regreso de José Castro Silva ${ }^{43}$. Enseguida, en editorial, El Tiempo cuestionó el papel de los consiliarios y la decisión de cerrar el plantel:

\begin{abstract}
Así, con corazón ligero, los consiliarios del Rosario [...] contra la voluntad unánime del profesorado, contra el querer del gobierno y de la sociedad, cuatro consiliarios asestan golpe de muerte al más ilustre de nuestros colegios, causan grave daño a jóvenes que allí seguían sus estudios, pero ponen a salvo su amor propio y tienen la satisfacción de proclamar que han hecho primar su voluntad por sobre todas las conveniencias públicas. Así se ha consumado este escándalo, sin precedentes quizá en nuestros anales educacionistas. [...] Una tonta obstinación de no acceder a los deseos de la opinión universitaria ha precipitado a los consiliarios a una cadena de errores, que culmina en el más inaudito de todos ${ }^{44}$.
\end{abstract}

Por su parte, el ministro Eliseo Arango destacó en entrevista a un periodista que la situación ponía al Gobierno en una posición difícil por el aspecto legal, pero a la vez reconocía que el conflicto tenía un carácter social que lo obligaba a intervenir. Desde luego, cuestionó la decisión de cerrar el plantel, perjudicando a los estudiantes, y de que la Consiliatura se apegara a las Constituciones que, a juicio del ministro Arango, eran malinterpretadas, ya que en ellas se estipulaba su adaptación de acuerdo al cambio de las circunstancias históricas ${ }^{45}$.

La decisión del gobierno de aplicar el decreto que ordenó la renovación de la Consiliatura, motivó a los consiliarios a expresar al ministro Arango la disposición de revocar el cierre del plantel, siempre y cuando los estudiantes hicieran una solicitud de reingreso, reconocieran las faltas cometidas y pidieran excusas. Por si esto fuera poco, los consiliarios se reservaban el derecho de aceptar o no las solicitudes de los estudiantes, sancionando a los promotores del movimiento de protesta ${ }^{46}$. Las exigencias desde luego fueron rechazadas por los estudiantes, quienes afirmaron que no se prestarían a un trato "ultrajante para su dignidad y su decoro"47. Los fortalecía el hecho de contar con el respaldo de la FNE y de los antiguos colegiales de número del colegio, quienes dirigieron un memorial a los consiliarios, solicitando la amnistía para los estudiantes.

\footnotetext{
43 "El doctor Arango propuso ayer una fórmula para arreglar el conflicto del Rosario", El Tiempo, Bogotá, 1 de julio de 1930, p. 1 y 13.

${ }^{44}$ Ibid.

45 "Demora el arreglo para el conflicto del Rosario", El Tiempo, Bogotá, julio 3 de 1930, pp. 1 y 8.

46 "Parece definitiva la renuncia de Barriga Villalba", El Tiempo, Bogotá, julio 5 de 1930, pp. 1 y 8; "Está de nuevo sin rector el colegio del Rosario", El Tiempo, Bogotá, julio 5 de 1930, pp. 1 y 8.

47 “14 rosaristas han sido expulsados”, Mundo al Día, Bogotá, 8 de julio de 1930, p. 2. La mayoría de los alumnos expulsados eran de la Facultad de Derecho, y hacían parte del comité de Huelga. Dos de ellos, Alejandro Venegas y Rafael González Torres, estaban entre los 21 estudiantes que el año anterior (1929) obtuvieron las más altas calificaciones en conducta y en rendimiento académico. Memoria del Ministro de Educación Nacional al Congreso de 1929 (Bogotá: Imprenta Nacional, 1929), p. 169.
} 
Los profesores, de otro lado, adelantaron reuniones para encontrar soluciones a la crisis. En ese ejercicio surgió la propuesta de pedir a los estudiantes su regreso a los claustros y cumplir con el reglamento interno, haciendo "prescindencia absoluta de la Consiliatura y del rector interino" 48 , mientras arribaba José Vicente Castro Silva, y se constituía un nuevo cuerpo de consiliarios. Por su lado, el ministro Arango intentó un acuerdo entre los consiliarios y los estudiantes, "sobre bases de equidad y de justicia"49, indicando que si se abría el camino de la conciliación, él intervendría para que los estudiantes retornaran al Rosario y concluyeran la huelga. Pero si los consiliarios y el rector Jenaro Jiménez no se prestaban a "un acuerdo amigable" procedería a resolver el conflicto de manera "enérgica y definitiva" 51 .

¿Podía el gobierno intervenir de manera vehemente en el conflicto del Colegio del Rosario, siendo wste un plantel autónomo $?^{52}$ Quienes defendían esa tesis, argüían que al gobierno no solo le asistía el derecho sino la obligación de intervenir, ya que el Colegio del Rosario era una entidad de servicio público, que, si bien se regía por reglamentos especiales que le conferían autonomía, al dejar de prestar el servicio para cuyo efecto había sido creado, obligaba al gobierno a intervenir para restablecerlo. Además, de no hacerlo, el gobierno se exponía a que se hiciera una acusación formal en el parlamento contra el ministro de educación.

El rector interino Jenaro Jiménez salió al paso a los reclamos del ministro Arango, manifestando que ni él ni los consiliarios habían desconocido el carácter de Patrono que las Constituciones le reconocían al Presidente de la república, ni habían desoído sus prerrogativas, en particular, sobre la elección de una nueva Consiliatura. No obstante, indicó que "[...] no sería propio ni ajustado a los miramientos debidos al futuro rector del colegio, anticiparse a formar la nueva consiliatura con prescindencia de su opinión y de su voto, ni seria ello adecuado para fomentar la completa armonía y unidad de miras entre el rector y los consiliarios" ${ }^{93}$. Sin duda, detrás de esta postura

48 “14 rosaristas han sido expulsados", Mundo al Día, Bogotá, julio 8 de 1930, p. 2. Firman la carta Alfonso E. Guzmán, Luis C. Olarte R., Carlos López Gómez, Gilberto Hoyos R., Carlos D. Afanador, M. Zúñiga V., Rafael García Solano, Alberto Escobar Ballesteros, Juan M. Pardo, Mariano Gutiérrez Romero Vanegas y Gustavo Suarez.

49 "La tragedia del Rosario", El Tiempo, Bogotá, 10 de julio de 1930, p. 5.

${ }^{50} \mathrm{El}$ nuevo rector levantó las sanciones a los alumnos expulsados el 26 de agosto de 1930. Guillen de Iriarte, María Clara, Op Cit; p. 553.

${ }^{51}$ Memoria del Ministro de Educación Nacional al Congreso (Bogotá: s.e., 1930), p. 74.

${ }^{52}$ En el Tercer Congreso Nacional de Estudiantes reunido en Ibagué en 1928, se había discutido como demanda especial, la intervención de los alumnos en el gobierno de los planteles como una expresión de la reforma universitaria. Gómez Martínez, Alberto y Martínez Simanca, Albio. Estudiantes y cambios generacionales en la sociedad colombiana (1910-1934) (Bogotá: Graficas Ducal, 2012), p. 193.

53 "La universidad de los colombianos", El Tiempo, Bogotá, 8 de julio de 1930, p. 4. Ocho días después de la publicación, Arciniegas leyó un discurso en la Universidad de Columbia (16 de julio), en donde, refiriéndose al papel de los universitarios en la historia de Hispanoamérica, destacó la importancia de la huelga estudiantil de 1930 en el Colegio del Rosario. Recordaba que hacía poco tiempo "[...] en el colegio del Rosario formularon los estudiantes bogotanos un programa de autonomía universitaria, pero antes llamaron la atención de la ciudad abandonando el edificio y trasladando los dormitorios a la Casa del Estudiante. A través de las calles principales se les vio desfilar con los colchones al hombro, mientras en las puertas del colegio se decían estas palabras: "Esta casa se alquila". "La vida universitaria en 
había una movida inteligente de Jiménez que se perfeccionó con el argumento de que, atendiendo el pedido del Presidente Abadía de realizar la elección de nuevos consiliarios, había enviado una comunicación al rector en propiedad, solicitándole su opinión, para lo cual Jiménez pedía "un poco de paciencia" 54 , hasta tanto se conociera la postura del rector titular, que, como se ha dicho, se encontraba fuera del país.

Jiménez también se refirió a la clausura del colegio, afirmando que había dado la orden de reanudar las labores, y que las puertas estarían abiertas a los rosaristas que quisieran ingresar, siempre y cuando acataran los reglamentos, ya que no era "[...] posible la vida en comunidad sin orden, sin disciplina y sin una completa armonía entre gobernantes y gobernados" ${ }^{55}$. Insistió en que los alumnos rebeldes -así los llamó- habían cometido faltas gravísimas, e invocó el factor divino para justificar la postura que había adoptado, ya que "[...] ni Dios mismo cuya misericordia es infinita puede perdonar al pecador que no solo se niega a arrepentirse, sino que persiste obstinadamente en rebelarse contra él" ${ }^{16}$.

\section{Renuncia el rector}

La postura del rector encargado, la presión de la prensa y la continuación de la huelga estudiantil, debieron haber incidido para que el gobierno tomara la decisión de pedir la renuncia de Jenaro Jiménez y nombrar a un nuevo rector interino. La decisión se basó en el razonamiento que hacia el ministro Arango: Jenaro Jiménez había sido nombrado rector en interinidad mientras se elegía un nuevo rector, la cual cesó desde el momento en que la Consiliatura hizo la elección de la terna y el presidente escogió a José Castro Silva. De modo que a Jiménez lo reemplazó Antonio María Barriga Villalba, egresado del plantel educativo en 1914, y quien gozaba de la simpatía de los estudiantes.

Una vez posesionado, Barriga Villalba se reunió con los miembros de la Consiliatura, a quienes les manifestó la conveniencia de cumplir el decreto del gobierno que establecía el nombramiento a la mayor brevedad de un nuevo cuerpo. Sin embargo, la solicitud fue desatendida por los consiliarios, quienes reiteraron estar a la espera del regreso del rector titular, al considerar que la elección debía "hacerse teniendo en cuenta

\footnotetext{
Hispanoamérica", El Tiempo, Bogotá, 30 de julio de 1930, p. 5.

54 "La generación de la reforma y la exclaustración de la cultura", El Tiempo, Bogotá, 16 de julio de 1930, p. 13. La conferencia del universitario Roberto Posada Zarate fue leída en la emisora HJN de Bogotá, el 1 de julio de 1930. El Colegio del Rosario era, en tal sentido, expresión de ese signo medieval, como lo creían ver sus críticos internos y externos: por ejemplo, los colegiales el día de su recepción como tales, debían jurar a Dios profesar la fe católica, acatar la constitución y leyes de la república, defender las Constituciones del Rosario y enseñar, llegado el caso, la filosofía según la mente del angélico doctor Santo Tomas de Aquino". Revista del Colegio del Rosario, Bogotá, p. 319.

55 “Los rosaristas contestan a don Tomas Rueda Vargas", El Tiempo, Bogotá, 28 de junio de 1930, p. 16. Firman el texto Héctor Martínez Guerra y Regulo María Niño.

${ }^{56}$ El caso de Diego Luis Córdoba así lo corrobora. De origen chocoano, Córdoba participó en el tercer congreso estudiantil reunido en Ibagué en 1928, de donde fue escogido como directivo del comité ejecutivo nacional de la agremiación, y posteriormente fue su presidente.
} 
la opinión y voluntad del nuevo director del colegio"57. Al fracasar en el propósito de conseguir que se cumpliera el decreto del ejecutivo, Barriga Villalba renunció ${ }^{58}$. Debió pesar el argumento de que tenía poco sentido ser la máxima autoridad de una institución donde su voz era desacatada.

La decisión de los consiliarios y la renuncia de Barriga Villalba provocaron la furia de los estudiantes. En la tarde del 6 de julio invadieron violentamente el colegio y la casa rectoral, causaron daños y amenazaron a varios colegiales. Enseguida, la Consiliatura reaccionó, expulsando a trece alumnos que habían tomado parte en los actos violentos: Juan B. Barrios, Regulo María Niño, Hernando Borrero Cuadros, Julio Tovar Quintana, Héctor Martínez, Joel Carrillo, Jesús Gómez Mejía, Isaí Gómez, Lisimaco Cárdenas, Jesús Estrada Monsalve, Alejandro Venegas, Rafael González Torres y Francisco A. Correa ${ }^{59}$.

Imagen 2. Viñeta que recrea el conflicto en el Colegio del Rosario.

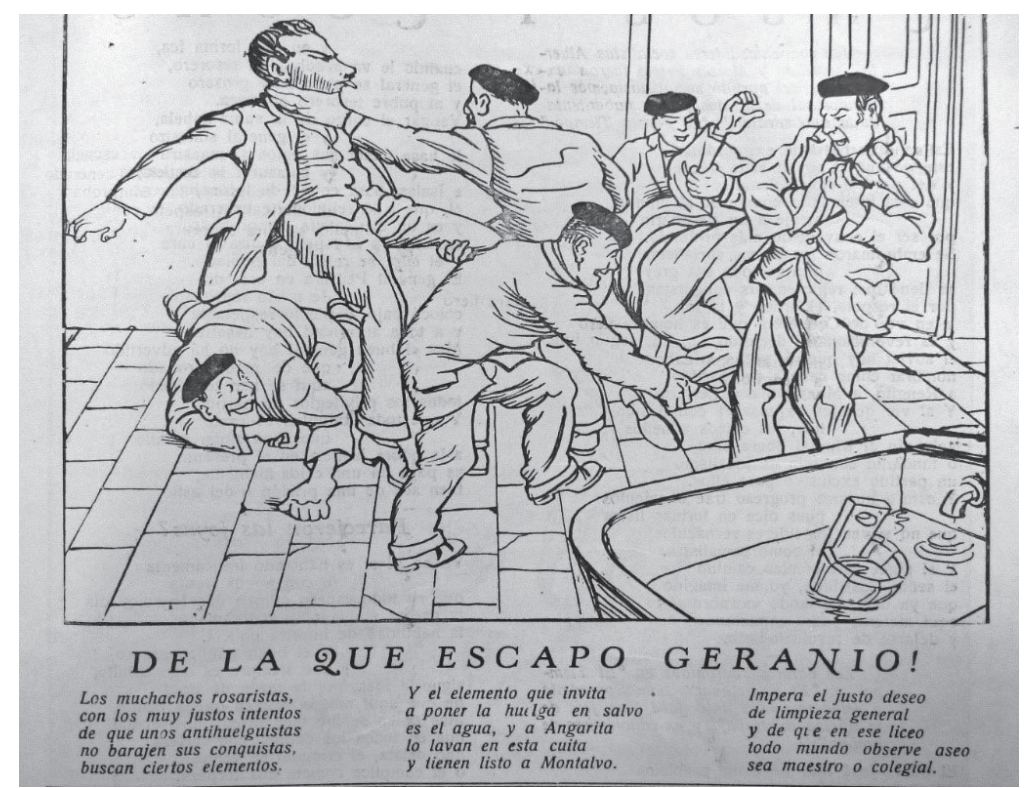

Fuente: Fantoches, Bogotá, 1930.

\footnotetext{
${ }^{57}$ Contrario de lo podría pensarse, fuera de Bogotá no hubo acciones destacadas de apoyo o solidaridad de estudiantes hacia el movimiento bogotano, aunque la huelga como acontecimiento fue informada por la prensa de otras ciudades del país. Que haya ocurrido así puede explicarse por la evidente debilidad que distinguía al gremio estudiantil a nivel nacional, algo por lo demás entendible si se tiene presente que, desde finales de los años treinta, dicho gremio registraba un proceso lento de debilitamiento como producto de las tensiones partidistas entre sus miembros.

58 "Los rosaristas quieren que se elija una nueva terna para rector", El Tiempo, Bogotá, 15 de junio de 1930, pp. 1, 13 y última. Muchos estudiantes, incluyendo a los del Colegio del Rosario, tuvieron la lectura de que con la llegada a la presidencia del liberal Enrique Olaya Herrera, la reforma universitaria sería una realidad. Se trató, sin embargo, de una lectura equivocada, "[...] porque los logros fueron tímidos y limitadas las realizaciones". Jaramillo Uribe, Jaime "La educación durante los gobiernos liberales. 1930-1946". Nueva Historia de Colombia (Bogotá: Planeta, 1989), p. 90.

${ }^{59}$ Para el caso español: Álvarez Cobelas, José. Envenenados de cuerpo y alma. La oposición universitaria al franquismo en Madrid (1939-1970) (Madrid: Siglo XXI de España, 2004), p. 294. Para el caso de América Latina, Solari, Aldo E. Estudiantes y política en América Latina (Caracas: Monte Ávila Editores, 1968), p. 58.
} 
Para evitar que la situación se agravara, el Presidente Abadía emitió un decreto en el que ordenó la admisión de los alumnos expulsados del Rosario, en la Facultad Nacional de Derecho, y a los de Literatura, en la Escuela Nacional de Comercio. Indignados por lo ocurrido, los estudiantes de literatura enviaron a los miembros de la Consiliatura una comunicación en donde expresaban su solidaridad con los alumnos expulsados. La reproducción en extenso del pronunciamiento, permite evidenciar el férreo carácter de los estudiantes que apoyaban la huelga:

Leyendo su decreto en que expulsan a unos de nuestros colegas, llegamos a la conclusión de que ustedes se propusieron, con una incomprensión inaudita, cerrar prácticamente el Colegio del Rosario; no somos incautos como ustedes malévolamente nos califican; ustedes están convencidos hasta la evidencia de que todos tomamos parte en la huelga y cualquiera actitud que se haya tomado y que muchos de nosotros hemos apoyado directamente, está respaldada por nuestra persona y por nuestro carácter y en este caso, de expulsión y cancelación de matrícula de sólo catorce de nuestros compañeros, consideramos la expulsión y cancelación de matrícula como hechas a cada uno de nosotros y si ustedes no tuvieron el valor moral suficiente para cobijar con su inteligente decreto a todos los que verdaderamente hemos tomado parte activa en todos los sucesos ocurridos y que lo motivaron, nosotros de una manera consciente y sin sugestiones de ninguna clase, como ustedes tristemente se lo han figurado de nuestra actitud en la huelga, y como jóvenes que tenemos carácter y dignidad, protestamos ante ustedes y ante la sociedad, que seguiremos a nuestros compañeros víctimas de la incomprensión de ustedes y que rechazamos enérgicamente las tacitas promesas que ustedes nos han venido haciendo de recibirnos de nuevo en el Colegio; ustedes han creído que en nuestros corazones jóvenes e inexpertos no se alvergaban (sic) sentimientos de generosidad, de nobleza y de sacrificio, y por ello han creído erróneamente que nosotros faltáramos a la sinceridad y al deber para con nuestros compañeros, pero no es así, y por eso rechazamos la "humillante y parcial indulgencia" que ustedes quieren prodigarnos, porque no queremos hacernos cómplices ni de la pretendida sanción que ustedes quieren imponer a unos pocos ni de la actitud antipatriótica y sin razón que ustedes han asumido para con nosotros ${ }^{60}$.

Así las cosas, los hechos últimos condujeron la crisis a un punto de no retorno. El "orgullo momificado de los señores consiliarios", como El Tiempo caracterizó el comportamiento de los miembros de la Consiliatura ${ }^{61}$, condujo a la efectiva clausura del colegio (aunque valga decir que en ese momento muchos estudiantes de Literatura y Derecho habían continuado sus estudios en la Universidad Libre y el Externado de Derecho, y en el Colegio Universitario y el Colegio Ramírez). Fue así que la huelga estudiantil llegó a su fin, como resultado del cierre del plantel educativo, que volvió

\footnotetext{
${ }^{60}$ Las apreciaciones del ministro Arango sobre la educación, pueden verse en reportajes y columnas periodísticas. "La educación pública constituye hoy nuestra mayor podredumbre, Eliseo Arango", El Tiempo, Bogotá, 1 de agosto de 1930, pp. 1 y 9; "Eliseo Arango y la educación pública", El Tiempo, Bogotá, 1 de agosto de 1930, p. 5 .

${ }^{61}$ Silva, Renán. "La educación en Colombia. 1880-1930”. Nueva Historia de Colombia (Bogotá: Planeta, 1989), p. 86.
} 
a abrirse en agosto, cuando se posesionó el rector oficial, José Vicente Castro ${ }^{62}$, y se constituyó una nueva Consiliatura, integrada por Tomas Rueda Vargas, Marcelino Uribe Arango y Antonio Gómez Restrepo, quienes fueron elegidos el 19 de agosto de 1930.

\section{Epílogo}

La huelga de estudiantes del Colegio Mayor del Rosario en 1930, tuvo una especial importancia, por razones que, a modo de síntesis, merecen ser resaltadas.

La huelga estuvo motivada por demandas que, desde tiempo atrás, venían planteando los estudiantes colombianos, y las cuales estaban articuladas a lo que se conocía como la "reforma universitaria", derivada del movimiento reformista de Córdoba (1918). De hecho, entre las demandas de los rosaristas, sobresalían cuestiones como la democratización de los planteles o, como se proponía desde 1918, la aspiración al cogobierno universitario. Al respecto, es de destacarse el influjo que tuvo la corriente reformista de Córdoba en los círculos universitarios de Colombia, lo cual se reflejó en los idearios que se agitaron en los tres congresos estudiantiles realizados entre 1924 y 1928, y que ubicaron como prioridad la reforma del sistema educativo. Esta reivindicación, como se sabe, fue postergada por las administraciones conservadoras, y en 1930, de nuevo, se convirtió en motivo de agitación en Bogotá.

En una columna periodística publicada por los días de la huelga de los rosaristas, German Arciniegas, un abanderado de la reforma en años anteriores, vio en ese conflicto una expresión del problema universitario que existía en Colombia, no resuelto, a su juicio, por culpa de los gobiernos conservadores, lo que imposibilitó que el país se adaptara a los requerimientos de la vida moderna. De ahí que insistiera en la "urgente necesidad de una reforma en los altos estudios". En el mismo sentido, el estudiante Roberto Posada Zarate expresó en una conferencia radial, también por aquellos días, que el momento de Colombia exigía "un nuevo tipo de Universidad", y que se debía despojar a la universidad colombiana del sello medieval que la caracterizaba en muchos aspectos.

Como se pudo mostrar, los estudiantes del Rosario invocaron la intervención del Estado en la crisis de la institución educativa, para lograr la modificación de las leyes que la regían, y que los marginaba de la participación en la elección de las autoridades que la dirigían. Se trataba, desde luego, de una demanda importante con la que buscaban ser reconocidos como actores significativos en la vida del colegio, como lo advertían al justificar su comportamiento rebelde en una comunicación dirigida a Tomas Vargas Rueda:

Las reuniones de los consiliarios tienen aspecto de kábalas (sic) o sesiones masónicas en las cuales se rodeaban de una aureola de misterio las venerables figuras de los miembros de la consiliatura. La distancia entre esos señores y nosotros era más grande que la existente entre el doctor Abadía y las tribus

62 "El problema fundamental de Colombia radica en la reforma educacionista", El Tiempo, Bogotá, 11 de julio de 1930, p. 4. 
goajiras (sic). La única vez que la Consiliatura habló oficialmente fue para amenazar con expulsión a quienes no se conformaron con la elección de terna para rector. Después de declarada la huelga todos los medios de conciliación se agotaron: las gestiones del señor ministro de educación, las de los profesores, las nuestras se estrellaron contra la impermeabilidad incomprensible de nuestros sabios consiliarios. Y para prueba allí está la primera carta al señor ministro, dirigida por la Consiliatura en la cual cerraron las puertas a toda voz de conciliación y avenimiento. Qué podíamos hacer ya? Resistir como lo hemos hecho y estamos dispuestos a hacerlo porque estando la justicia de nuestra parte será nuestra la victoria.

Opiniones de este tenor permiten identificar el debate que se abrió paso, sobre la necesidad de emprender una reforma en el sistema educativo universitario, demanda que, por cierto, explica el apoyo que recibieron los rosaristas de la FNE y del Centro Departamental de Estudiantes, gremios dirigidos por líderes estudiantiles que estaban plenamente imbuidos del discurso reformista de 1918.

Como expresión de la acción colectiva, la huelga del Rosario recreó formas de lucha empleadas por los estudiantes de la capital desde la década anterior, y que se pusieron en práctica una vez se originó la oportunidad política. Es de destacar que los estudiantes hubiesen tomado la decisión de declarar una huelga en un establecimiento educativo como el Colegio del Rosario, sobre todo, que hubiesen tenido la disposición de sostenerla, sin temor a perder la calidad de matriculado, desafiando abiertamente a las autoridades del plantel. Como se demostró en su momento, incidió en el comportamiento de los estudiantes los apoyos diversos que recibieron, destacándose el de la prensa liberal y de universitarios de otros planteles educativos de la ciudad; además, desde una lectura que privilegia la estructura de oportunidad, es evidente el hecho de que los estudiantes hayan tenido presente el cambio de régimen político y advirtieran la posibilidad de obtener una victoria a su favor, con el arribo a la presidencia del liberal Enrique Olaya Herrera, quien se posesionaría en agosto de ese año.

Al revisar los repertorios de lucha que fueron empleados por los estudiantes durante la huelga, sobresale la decisión que adoptaron de abandonar el Colegio del Rosario como medida de presión, un recurso poco común hasta ese momento en la historia de los conflictos estudiantiles en el país (aunque se aplicó en otros contextos y en épocas diferentes). Como se advirtió, la determinación de los estudiantes de abandonar el plantel tuvo un efecto simbólico difícil de soslayar, al haber generado una especie de vacío de poder que no pudo remediar ni la Consiliatura ni el rector interino.

De otro lado, la huelga del Rosario de 1930 puso en evidencia el peso de la FNE en Bogotá y el papel que continuaba desempeñando la Casa del Estudiante, como espacio de sociabilidad política. Surgida en 1924, la edificación sirvió para que los estudiantes federados de la capital tuvieran un espacio para la distracción y solventaran algunas necesidades de tipo material; sin embargo, también se convirtió en un lugar fundamental para sostener debates e incluso conspirar en ciertas coyunturas, como ocurrió durante la huelga. Estas particularidades fueron especialmente notorias en el conflicto estudiantil de 1930. 
La solidaridad estudiantil, tal y como se resaltó, fue un factor importante que sirve para explicar en parte la persistencia de la huelga, y expresa los grados de integración o de articulación que existía entre los estudiantes en la capital del país. Para sostener la huelga, por ejemplo, los rosaristas desplegaron junto a compañeros de otras instituciones educativas, actividades que involucraron a las candidatas del reinado estudiantil, y a artistas famosos de la época, que ofrecieron funciones culturales a beneficio de los rosaristas.

Finalmente, el conflicto estudiantil permitió evidenciar las tensiones que parecían existir al interior del conservatismo en el poder, por la cuestión de la reforma educativa. En efecto, los hechos mostraron al primer mandatario dubitativo para actuar, pero por otro lado, a un Ministro de Educación, partidario de la reforma educativa y un aliado de los estudiantes en sus demandas. Esto demostraría que, como lo indicó un estudio sobre la educación de aquel momento, la reforma educativa "[...] involucró a grupos intelectuales y a movimientos de ideas más amplios de los que se señalan regularmente". Es decir, que en el debate sobre la reforma del sistema educativo en el país, no solo los liberales fueron los principales interesados, como suele siempre destacarse, sino además sectores del conservatismo interesados en la modernización social. Si bien era de afiliación conservadora, el ministro Eliseo Arango se mostró partidario, como lo hacían políticos e intelectuales liberales, de modernizar la educación pública, considerada por el ministro como la "mayor podredumbre y pobreza" del país. En el informe que presentó en el Congreso en julio de 1930, pronto a concluir el gobierno conservador, el ministro Arango afirmó con dureza, refiriéndose a los retos que tenía el Estado frente al tema de la educación:

Es necesario que el país no se siga engañando con una oficina que lleva el nombre de Ministerio de Educación Nacional. Lo que principalmente existe es un despacho encargado de suministrar recursos para las leproserías, sanidad, beneficencia, y que tiene modestos aportes para la enseñanza pública. Modestos en relación con la magnitud de la obra.

\section{Fuentes}

\section{Fuentes primarias}

\section{Informes oficiales}

Memoria del Ministro de Educación Nacional al Congreso de 1929. Bogotá: Imprenta Nacional, 1929.

Memoria del Ministro de Educación Nacional al Congreso. Bogotá: Imprenta Nacional, 1932. 


\section{Publicaciones periódicas}

Cromos, Bogotá, 1930.

El Diario Nacional, Bogotá, 1930.

El Tiempo, Bogotá, 1930.

Fantoches, Bogotá, 1930.

Mundo al Día, Bogotá, 1930.

Revista del Colegio Mayor de Nuestra Señora del Rosario, Bogotá, 1930.

Revista Jurídica, Bogotá, 1927.

\section{Fuentes secundarias}

\section{Libros}

Álvarez Cobelas, José. Envenenados de cuerpo y alma. La oposición universitaria al franquismo en Madrid (1939-1970). Madrid: Siglo XXI de España, Madrid.

Arias, Ricardo. Los Leopardos. Una historia intelectual de los años 1920. Bogotá: Uniandes-Ceso, 2007.

Gaitán Bohórquez, Julio. El Colegio del Rosario y el proyecto decimonónico de universidad en Colombia: un intento de reconstrucción desde la normatividad. Bogotá: Universidad del Rosario, 2002.

Gómez Martínez, Alberto y Martínez Simanca, Albio. Estudiantes y cambios generacionales en la sociedad colombiana (1910-1934). Bogotá: Graficas Ducal, 2012.

Guillen de Iriarte, María Clara. Rectores y rectorías del Colegio Mayor de Nuestra Señora del Rosario 1653-2003. Bogotá: Academia Colombiana de Historia, 2003.

Guillen de Iriarte, María Clara. Los estudiantes del Colegio Mayor de Nuestra Señora del Rosario 1826-1842. Bogotá: Editorial Universidad del Rosario, 2008.

Mayorga García, Fernando. El Estado y el Colegio del Rosario en el siglo XIX: una historia de luces y sombras. Bogotá: Editorial Universidad del Rosario, 2010.

Ortiz Rodríguez, Álvaro Pablo. Historia de la Facultad de Filosofia y Letras del Colegio Mayor de Nuestra Señora del Rosario 1930-1999. Bogotá: Editorial Universidad del Rosario, 2006. 
Solari, Aldo E. Estudiantes y politica en América Latina. Caracas: Monte Ávila Editores, 1968.

\section{Capítulos de libro}

Jaramillo Uribe, Jaime. "La educación durante los gobiernos liberales. 1930-1946”, en Nueva Historia de Colombia. Bogotá: Planeta, 1989.

Silva, Renán. “La educación en Colombia. 1880-1930”, en Nueva Historia de Colombia. Bogotá: Planeta, 1989.

Soto Arango, Diana. "El movimiento de estudiantes y catedráticos en Santa Fe de Bogotá a fines del siglo XVIII", en Marsiske, Renate (coord.), Movimientos estudiantiles en la historia de América Latina, tomo I. México D.F.: Universidad Autónoma de México, 1999. 